\title{
System dynamics to design an educational game for improving interpersonal skills to manage conflict
}

\author{
Hiromichi TAKAHASHI* and Masaru NAKANO* \\ *Graduate School of System Design and Management, Keio University \\ 4-1-1 Hiyoshi, Kohoku-ku, Yokohama, Kanagawa 223-8526, Japan \\ E-mail: hiro.takahashi@keio.jp
}

Received: 21 July 2018; Revised: 17 March 2019; Accepted: 6 May 2019

\begin{abstract}
This research discusses how system dynamics is used to develop an educational game, called CANDY OG, to learn how to improve supply chain performance under conflict of key performance indicators (KPIs). Its objective is to explore applicability of system dynamics to design a business game for fostering interpersonal skills. A causal loop diagram is used to confirm the game design so that the participants can learn by playing about importance of understanding other stakeholder's mental model to improve supply chain performance. The game was played for experiments to evaluate effectiveness of the game design by surveys and other qualitative methods such as samples' memos during the game, follow-up interviews and participatory observations. Our experimental results suggest a possibility that the game provides experiential learning to develop interpersonal skills at managing conflicts of KPIs, and thus indicate that the use of system dynamics helps to ensure appropriate designing of the game. The originality is a use of system dynamics for designing an educational game, leveraging its capability to analyze mental models of stakeholders in a system.
\end{abstract}

Keywords: Supply chain management, Production management, Flexible production system, Interpersonal skills, System dynamics, Causal loop diagram, Key performance indicator (KPI), Experiential learning

\section{Introduction}

A supply chain is defined as a network of connected and interdependent organizations mutually and co-operatively working together to produce value in the form of products and services to end users (Christopher 1998). To fulfill a customer order, organizations in a supply chain are engaged interdependently throughout the value stream from sourcing through production to delivery (Hassini 2008; Supply Chain Operations 2010) Accordingly, supply chain management is defined as "the management of upstream and downstream relationships with suppliers and customers to deliver superior customer value at less cost to the supply chain as a whole" (Christopher 1998).

Supply chain management uses multiple measurements strategically defined for planning, monitoring and managing performance of processes, so-called key performance indicators (KPIs). The Supply Chain Operations Reference (SCOR) model proposes a balanced measurement system of KPIs, covering five end-to-end supply chain processes (i.e. Plan, Source, Make, Delivery, and Return) (Cai et al. 2009). Typical KPIs in supply chain management include (i) fill rate - "the percentage of orders delivered on time"- (ii) delivery delay - actual delivery time (or day) minus confirmed delivery time (or day), (iii) sales, and (iv) inventory turnover ratio (Kleijnen \& Smits 2003).

Multiple disciplines are applied for optimization of supply chain performance. First, utility theory in economics applies to set utility as the final performance measure of a supply chain, using multiple KPIs as its attributes (Kleijnen \& Smits 2003). Then, to solve optimization problems of supply chain performance, mathematical models and simulation tools are frequently discussed (Asgari et al. 2016). The use of information technology is also considered to enhance supply chain optimization (Ding et al. 2011). For example, enterprise resource planning systems such as SAP 
and Oracle provide support for measuring and monitoring KPIs to optimize supply chain performance of organizations (Cai et al. 2009). On the other hand, as general Game Theory states, the optimal performance of a supply chain cannot be achieved by the organizations that individually attempt to optimize their own performance. Hence, collaboration is still foundational to improve supply chain performance beyond a level which each organization would be able to achieve by itself.

In 1995, SAP started supporting a joint project of Wal-Mart and Warner-Lambert called Collaborative Planning, Forecasting and Replenishment (CPFR), which aimed at drastic reductions of inventories (Panahifar et al. 2015). The organization, the Efficient Consumer Response Movement ("ECR"), later defines CPFR as "a cross-industry initiative designed to improve a supply chain through co-managed planning processes and shared information", emphasizing inter-company efforts (Skjoett - Larsen et al. 2003). Parung and Bititci further state that collaboration can be accomplished and sustained by mutually defining KPIs and KPI attributes among organizations (2008).

However, some KPIs such as fill rate and inventory turnover, are negatively correlated (Kleijnen \& Smits 2003). In a context of encountering conflict of behaviors that are aimed at improving different KPIs ("Conflict of KPIs"), collaboration among organizations involves the following challenges:

- $\quad$ "challenges related to human interactions and biases,

- $\quad$ challenges due to traditional behaviors, and

- challenges in communication and defining accountability" (Panahifar et al. 2015).

Even for supply chain organizations belonging to a single company, Conflict of KPIs creates conflict among the organizations in a supply chain.

Goal Setting Theory states that it is important to set personal goals that are compatible with the group's goal; this also applies to goal setting between organizations (Locke \& Latham 2006). However, there is Conflict of KPIs among intracompany organizations such as the conflict arising from negative correlation between fill rate and inventory turn-over. There is also Conflict of KPIs among intercompany organizations such as that attributable to generally known trade-off between the lot sizes of delivery and production costs. Therefore, it is not easy to define and share KPIs for collaboration goals until organizations in a supply chain, whether intracompany or intercompany, have committed themselves to collaboration.

Therefore, supply chain management is required to develop talents who can manage Conflict of KPIs and enhance collaboration to improve supply chain performance. In this research, a business game is considered as one of the solutions that assist supply chain management's attempts to satisfy the requirement.

Beer Distribution Game has been one of the most widely used business games for more than a half century. It was first developed by MIT in the 1960s as a board game involving role-playing of the production and distribution system of a single product. It creates a context where each organization does not have global information but owns good local information (Sterman 1989). Participants in the game realize that a lack of global information induces irrational behaviors of organizations and their interactions in the supply chain; it creates aggregate dynamics, a so-called bullwhip effect, to diverge from global optimization (Sterman 1989; Kaminsky \& Simchi-Levi 1998).

System dynamics is "a perspective and set of conceptual tools that enable us to understand the structure and dynamics of complex systems" (Sterman 2000). The Beer Distribution Game is applied as a logistic model for explaining system dynamics by demonstrating a systemic tendency of a supply chain due to a time delay in balancing loops called the "bullwhip effect" (Kriz W., 2003). At the same time, system dynamics is often applied to research on bounded rationality and misperceptions of feedback, an effect of limited information and biases, using experimental models created by the Beer Distribution Game.

However, system dynamics has not been used to design a business game to enhance learning from interactions among participants, by describing the mental model. Hence, the aim of this research is to explore the applicability of system dynamics to design an educational game to develop talents who can manage Conflict of KPIs for improving supply chain performance.

Section 2 introduces the game overview. Section 3 discusses the game design and opportunities of applying system dynamics for reviewing the game concept and for identifying how to enrich learning experiences from interactions with other participants. Section 4 summarizes the experimental method and results. Section 5 then discusses additional research opportunities that this research identifies. Section 6 concludes that the experimental results shows an indication that system dynamics is an effective design tool of an educational game for enhancing interpersonal skills. 


\section{Game Overview}

The game is called CANDY OG, the acronym of "Collaboration AND Your Own Goal." (the Game), aiming at providing an opportunity to learn how to improve supply chain performance under Conflict of KPIs. Table 1 outlines the Game.

Table 1 Outline of the Game.

\begin{tabular}{|c|c|}
\hline 1. Key Objectives & $\begin{array}{l}\text { To acquire and improve skills required for improving supply chain } \\
\text { performance, by understanding: } \\
\text { a Conflict of KPIs, } \\
\text { b The importance of managing control variables that positively } \\
\text { affect both parties, and } \\
\text { c Importance of collaboration. }\end{array}$ \\
\hline 2. Number of Participants & Between 5 and 10 per each of multiple groups \\
\hline 3. Duration of Game & 3 hours \\
\hline
\end{tabular}

As shown in Fig. 1, a supply chain structure is designed with a two-tier supply chain ("SC"), which supplies the finished goods to a single wholesaler ("Customer"). Within this structure, there are two suppliers ("Suppliers") of two components ("Components") each. Supplier AB produces Component A and Component B, while Supplier CD does Component $\mathrm{C}$ and Component D. There are two manufacturers ("Manufacturers") of one finished goods ("Finished Goods") each. Manufacturer AD assembles Component A and Component D into Finished Goods AD, while Manufacturer BC does Component B and Component $\mathrm{C}$ into Finished Goods BC. Table 2 describes each of Components and Finished Goods, including their flows and bill of materials.

Suppliers and Manufacturers compete, negotiate or collaborate to attain their goal in three rounds of the Game, as defined in Table 3 and Table 4. At the end of each round, Suppliers, Manufacturers confirms their transactions of Components and Finished Goods, including defects and backorders, and inventory to compute their Income per Table 5 and Table 6. Debriefing follows each round to enhance participants' learning by facilitating their reflection from their experience.

In each round of ten minutes, Customer simultaneously places orders for Finished Goods AD and Finished Goods $\mathrm{BC}$ to Manufacturer AD and Manufacturer BC, respectively, every two and a half minutes. Delivery for each order is also cut off every two and a half minutes. Receiving the orders from Customer, each Manufacturer issues Component orders to respective Suppliers at any time for any quantity (See Order Flow in Fig.1); for instance, Manufacturer may split orders into small quantity to minimize inventory. Or, he may make even a larger order to build up their safety stock or to occupy Suppliers' time for interrupting the other Manufacturer's sourcing activity. Manufacturer needs to determine his own strategy regarding order placement, per sales lot size, unit inventory cost and unit penalty for backorder of Components and Finished Goods as listed in Table 5 and Table 6 and any other information he collects.

Receiving the orders from Manufacturers, Supplier chooses which of the two Components to assemble at a time. He may then deliver the Component to respective Manufacturer at any time. Receiving Component from Supplier,

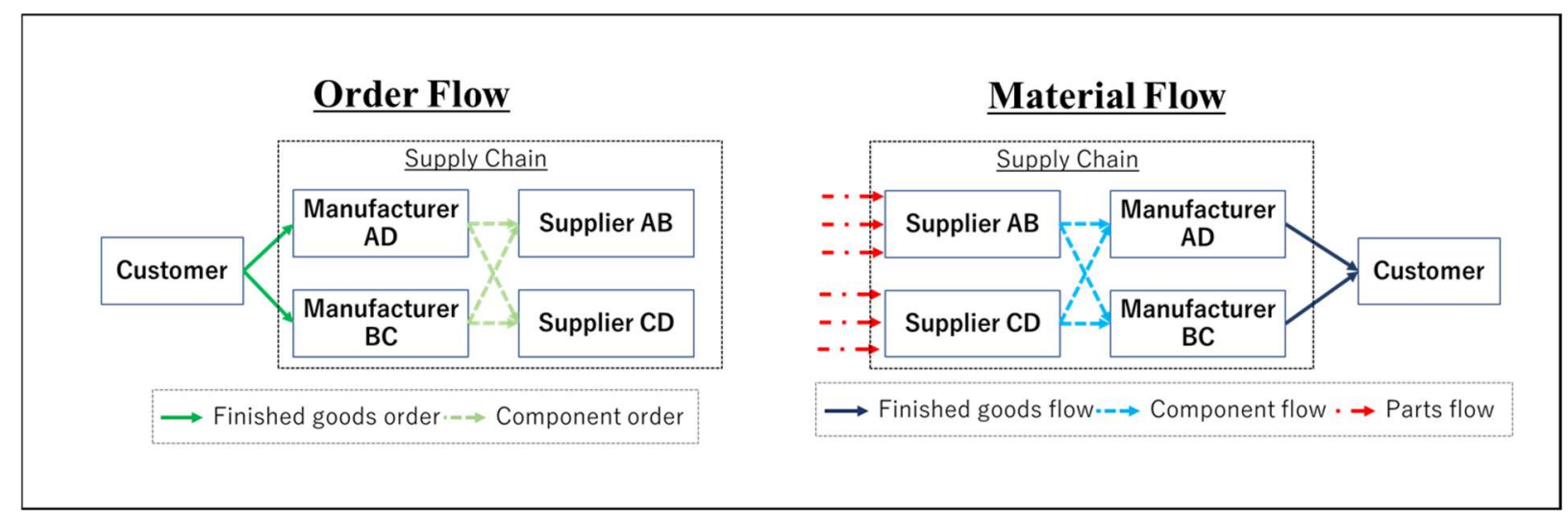

Fig. 1 Two-Tier Supply Chain Structure of the Game. 
Manufacturer inspects and rejects any defective Component. Manufacturer assembles and delivers Finished Goods to Customer (See Material Flow in Fig. 1) by the cut-off time, two and a half minutes from receiving the order. Supplier should determine their own strategy regarding their production plan not only per sales lot size, lot price, unit penalty for defect and unit inventory cost (see Table 5), but per his expected cycle time and any other information available to him.

Manufacturer returns defective Components and charge penalty to respective Supplier. The Supplier may fix the defects and deliver the Components to the Manufacturer to make up a delivery of the sales lot size. The same applies to Customer and Manufacturers for defective Finished Goods.

Table 2 List of Components and Finished Good.

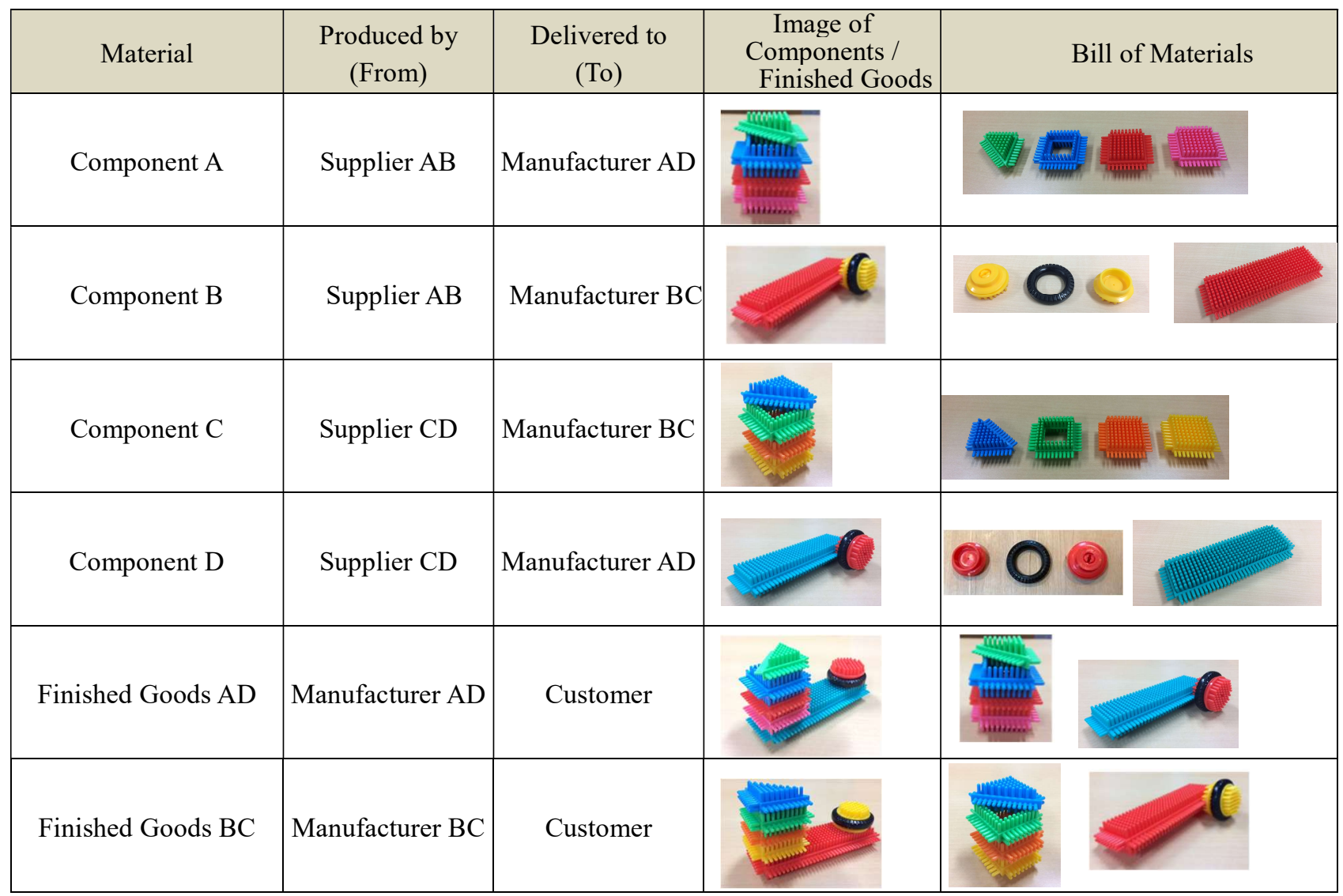

Table 3 Change of Goal and Rules over Rounds.

\begin{tabular}{|c|c|c|}
\hline Round Name & Goal & Rules \\
\hline $\begin{array}{c}\text { Round } 1 \\
\text { (Competition) }\end{array}$ & $\begin{array}{l}\text { Maximize } \\
\text { individual Income } \\
\text { (See Table 4) }\end{array}$ & $\begin{array}{l}\text { - Compete with other participants, per the trading terms and } \\
\text { operational factors as listed in Table } 5 \text { and Table } 6 \text {. } \\
\text { Communication with other roles about strategic decisions is not } \\
\text { allowed. }\end{array}$ \\
\hline $\begin{array}{c}\text { Round } 2 \\
\text { (Negotiation) }\end{array}$ & (ditto) & $\begin{array}{l}\text { - Before playing, the participants form a pair of one Supplier and } \\
\text { one Manufacturer, and negotiate on the trading terms and other } \\
\text { operational factors among each pair. They alternate } \\
\text { counterparts and negotiate. } \\
\text { The trading terms with the Customer (See Table 6) and Unit } \\
\text { Inventory Costs for Supplier and Manufacturers (See Table } 5 \\
\text { and Table 6) cannot change. }\end{array}$ \\
\hline $\begin{array}{c}\text { Round } 3 \\
\text { (Collaboration) }\end{array}$ & $\begin{array}{l}\text { Maximize SC's } \\
\text { total income }\end{array}$ & $\begin{array}{l}\text { Collaborate among the four roles of SC. Their operational } \\
\text { conditions can change as far as agreed. While the trading } \\
\text { terms with the Customer and Unit Inventory Cost cannot } \\
\text { change, there is no need to discuss their trading terms among } \\
\text { the four. }\end{array}$ \\
\hline
\end{tabular}


Table 4 Measurement of Income.

\begin{tabular}{|c|c|}
\hline Role & Measurement of Income (KPI) \\
\hline Supplier & Component revenue ${ }^{(1)}-$ Penalty paid for defect ${ }^{(1)}-$ Inventory cost \\
\hline Manufacturer & $\begin{array}{l}\text { Finished Goods revenue }+ \text { Penalty received for Suppliers' defects }{ }^{(1)}-\text { Component } \text { cost }^{(1)} \\
\text { - Penalty paid for backorder }- \text { Penalty paid for defect }- \text { Inventory cost }\end{array}$ \\
\hline
\end{tabular}

Note 1: Supplier's component revenue and penalty paid for defect are equal to Manufacturer's component cost and penalty received for the Suppliers' defects, respectively.

Table 5 Initial Trading Terms, Inventory Cost and Cycle Time of Components.

\begin{tabular}{|c|c|c|c|c|c|c|}
\hline \multirow[b]{2}{*}{ Material } & \multicolumn{4}{|c|}{ Initial Trading Terms ${ }^{(1)}$} & \multirow[b]{2}{*}{ Inventory Cost } & \multirow[b]{2}{*}{ Cycle Time ${ }^{(2)}$} \\
\hline & $\begin{array}{l}\text { Sales Lot } \\
\text { Size }\end{array}$ & Price ${ }^{(3)}$ & Penalty for Defect & $\begin{array}{l}\text { Penalty for } \\
\text { Backorder }\end{array}$ & & \\
\hline $\begin{array}{c}\text { Component } \\
\text { A \& C }\end{array}$ & 4 Units & $\$ 2,000 /$ Lot & $\Delta \$ 500 /$ Unit & N.A. & $\boldsymbol{\Delta} \$ 200 /$ Unit & 20-30 sec./Unit \\
\hline $\begin{array}{c}\text { Component } \\
\text { B \& D }\end{array}$ & 8 Units & $\$ 2,000 /$ Lot & $\Delta \$ 200 /$ Unit & N.A. & $\boldsymbol{\Delta} \$ 200 /$ Unit & 10-15 sec./Unit \\
\hline
\end{tabular}

Note 1: Initial trading terms can change through negotiation in Round 2, while unit inventory cost does not change.

Note 2: Unit cycle time is the expected range of cycle time for Supplier to produce one unit of Component per the Components design. Actual cycle time depends on Supplier's skills but can be is a control variable as discussed in Section 3.3.

Note 3: Any fractional unit of Sales Lot Size is not paid. For instance, only $\$ 2,000$ is paid for 7 units of Component A received in a round.

Table 6 Trading Terms, Inventory Cost and Cycle Time of Finished Goods.

\begin{tabular}{|c|c|c|c|c|c|c|}
\hline \multirow[b]{2}{*}{ Materials } & \multicolumn{4}{|c|}{ Trading Terms } & \multirow[b]{2}{*}{ Inventory Cost } & \multirow[b]{2}{*}{ Cycle Time ${ }^{(1)}$} \\
\hline & $\begin{array}{c}\text { Sales Lot } \\
\text { Size }\end{array}$ & Price & Penalty for Defect & $\begin{array}{l}\text { Penalty for } \\
\text { Backorder }\end{array}$ & & \\
\hline $\begin{array}{c}\text { Finished Goods } \\
\text { AD \& BC }\end{array}$ & 1 Unit & $\$ 2,000 /$ unit & $\mathbf{\Delta} \$ 2,000 /$ Unit & $\begin{array}{c}\mathbf{\Delta} \\
\$ 1,000 / \text { Unit }\end{array}$ & $\boldsymbol{\Delta} \$ 200 /$ Unit & 20-30 sec./Unit \\
\hline
\end{tabular}

Note 1: Unit cycle time is the expected range of cycle time for Manufacturer to assemble one unit of Finished Goods per the Finished Goods design. Actual cycle time depends on Manufacturer's skills but can be a control variable as discussed in Section 3.3.

Since Suppliers and Manufacturers aim at maximizing their own Income in the first two rounds, the Game creates Conflict of KPI. Penalties for Backorder and for Defect cause players motivations to consider of timely delivery and quality, respectively. The two-tier SC structure causes more specific conflict. If Manufacturer fails to receive enough Components from both Suppliers in time, he cannot continue to produce his Finished Goods, resulting in backorders. Since Suppliers are not subject to a backorder penalty but Manufacturers are as shown in Table 5 and Table 6, it sets clear difference of their motivations and amplifies Conflict of KPI between Suppliers and Manufacturers. So, sourcing process of Manufacturers from Suppliers becomes a bottleneck of this SC; i.e. starving of Components for manufacturing of Finished Goods affect Manufacturers' backorders and overall SC's performance. In addition, if he fails to receive Components from both Suppliers at the same pace, he cannot consume all the Components received from either Supplier, causing Inventory cost. Thus, it is crucial for a Manufacturer to get an allocation of both Suppliers' time to produce for his orders, i.e. to get a higher priority from both Suppliers than the other Manufacturer.

On the other hand, the time limit for Supplier is determined by the duration of each round, so the Supplier cannot fulfill all orders from both Manufacturers. To optimize their KPIs, Supplier assesses the profitability of the two Components per KPI measurement as defined in Table 4. Supplier determines how many units of which Components 
he produces at a time, when he receives orders from both Manufacturers. So, Supplier's time constraint is a major source of conflict in the Game when each of the Suppliers and Manufacturers tries to maximize his KPI.

\section{Game Design}

This section discusses the application of system dynamics to develop the Game design, after setting the key requirements for the Game design.

To deprive the key requirements for the Game, Beer Distribution Game is benchmarked as shown in Table 7. Beer Distribution Game is often used to explain a systemic effect of supply chain, called a bullwhip effect. In contrast, the Game is to provide experiences to manage interactions with others especially under Conflict of KPI. The participants are expected to learn from reflections of their interactions, including their observations of other participants' interests, decisions and behaviors, as well as of how successful their own decision and behaviors are to influence other participants. As the Game design aims at magnifying influence of interactions with the other participants on his performance, Table 8 defines the three key requirements for the Game design ("Key Requirements") to apply system dynamics.

Table 7 Comparison of Beer Distribution Game and CANDY OG.

\begin{tabular}{|c|c|c|}
\hline & Beer Distribution Game & CANDY OG \\
\hline A. Type of game & Board Game & Board Game \\
\hline $\begin{array}{l}\text { B. Number of } \\
\text { tiers in SC }\end{array}$ & $\begin{array}{l}\text { Four, including Retailer, Wholesaler, } \\
\text { Distributor, and Factory }\end{array}$ & $\begin{array}{l}\text { Two, including Manufacturers and Suppliers } \\
\text { (See Fig.1) }\end{array}$ \\
\hline $\begin{array}{l}\text { C. Order \& } \\
\text { material flow }\end{array}$ & One line & $\begin{array}{lccc}\text { Four lines between } & \text { Suppliers and } \\
\text { Manufacturers (See Fig.1) } & & \\
\end{array}$ \\
\hline $\begin{array}{l}\text { D. Materials to } \\
\text { flow in SC }\end{array}$ & One type of material, i.e. beer bottle cap & $\begin{array}{l}16 \text { types of parts, four types of components } \\
\text { and two types of finished goods (See Table 2) }\end{array}$ \\
\hline E. Game's goal & $\begin{array}{l}\text { To minimize the sum of inventory carrying } \\
\text { cost and opportunity cost for backorder }\end{array}$ & $\begin{array}{l}\text { Net revenue from trading, reflecting } \\
\text { backorder, defect and inventory (See Table } 3 \\
\text { and Table 4) }\end{array}$ \\
\hline $\begin{array}{l}\text { F. Primary } \\
\text { learning point }\end{array}$ & $\begin{array}{l}\text { Bullwhip effect, a systemic tendency, in } \\
\text { Supply Chain caused by time delay of } \\
\text { balancing loops }\end{array}$ & $\begin{array}{l}\text { Interactions effect in Supply Chain } \\
\text { attributable to individuals' priority of actions } \\
\text { determined under conflict of KPI }\end{array}$ \\
\hline $\begin{array}{l}\text { G. Associated } \\
\text { learning }\end{array}$ & $\begin{array}{l}\text { Importance of information shared to mitigate } \\
\text { time delay of balancing loops }\end{array}$ & $\begin{array}{l}\text { Importance of understanding stakeholders' } \\
\text { mental model to determine their priority of } \\
\text { actions }\end{array}$ \\
\hline $\begin{array}{l}\text { H. Variations of } \\
\text { learning } \\
\text { experiences }\end{array}$ & $\begin{array}{l}\text { Limited to effects of heuristics participants } \\
\text { may select. Gameplay continues without any } \\
\text { change in supply chain context. }\end{array}$ & $\begin{array}{l}\text { Variations of learning from different contexts } \\
\text { in three Rounds that cause behavioral } \\
\text { changes, in addition to effects of social and } \\
\text { technical skills and heuristics }\end{array}$ \\
\hline $\begin{array}{l}\text { I. Opportunities } \\
\text { of repeated } \\
\text { play }\end{array}$ & $\begin{array}{l}\text { Limited learning after learning about the } \\
\text { systemic tendency }\end{array}$ & $\begin{array}{l}\text { Effective learning by playing different roles } \\
\text { or with different participants }\end{array}$ \\
\hline $\begin{array}{l}\text { J. Information } \\
\text { available to } \\
\text { participants }\end{array}$ & $\begin{array}{l}\text { Limited to: } \\
\text { - Orders received from his immediate } \\
\text { upstream } \\
\text { - His own inventory, and } \\
\text { - Orders placed to his immediate } \\
\text { downstream. }\end{array}$ & $\begin{array}{l}\text { In addition to the available information in } \\
\text { Beer Distribution Game, participants can see } \\
\text { one another during the gameplay, and } \\
\text { understand status of all the other participants. }\end{array}$ \\
\hline $\begin{array}{l}\text { K. Judgement } \\
\text { required }\end{array}$ & Order volume to place & $\begin{array}{l}\text { Manufacturers: volume and timing to order } \\
\text { to Suppliers, and timing to deliver to } \\
\text { customer (before cut-off time). } \\
\text { Suppliers: volume and timing to supply to } \\
\text { Manufacturers. }\end{array}$ \\
\hline
\end{tabular}


Table 8 Key requirements for Game Design.

The Game creates:
A. No systemic tendency of each role's behaviors
B. Participants' need to understand other participants' mental model to optimize their performance, and
C. Different contexts to change participants' behaviors.

While general requirements for pedagogy, gameplay, user-interfaces and debriefing etc. discussed by conventional studies still apply (Raybourn 2007; Domínguez et al. 2013; Crookall 2011; Winn 2009), system dynamics tools (Sterman 2000) are used to confirm the possibility of the Game design to meet the Key Requirements.

\subsection{Design to Create No Systemic Tendency}

A causal loop diagram ("CLD") is a system dynamic tool to illustrate the feedback structure of a system of interests using arrows that connect two variables from a cause to an effect to show causal relations; a CLD is instrumental for deriving and presenting the mental models of individuals or teams (Sterman 2000). A stock and flow map ("SFM") is also used in system dynamics to emphasize causal loop relations by tracking accumulations of material and information by means of their transactions through a system (Sterman 2000). In this research, SFM is not used to quantitatively simulate the Game, but to incorporate accumulations of Manufacturers' order into a CLD. The CLD is used to examine the factors for Supplier's forming his priority over Components to produce at a time.

Figure 2 shows that the following six key variables affect Supplier AB's priority of producing Component A over Component B (S-AB Component Priority), as an example:

1) Supplier AB's comparative profitability of producing Component A against producing Component B ("S-AB Profitability"),

2) Supplier AB's comparative perception of risk of paying penalties for defects by producing Component A against Component B ("S-AB Defect Risk"),

3) Supplier AB's need to change production tasks from Component A to Component B ("S-AB Production Change-Over"), which Supplier may be inclined to avoid as far as possible to maintain his productivity and mitigate Defect Risk,

4) Supplier AB's comparative perception of timely delivery assurance to fulfill an order for Component A against that for Component B ("S-AB Timely Delivery Assurance"), and

5) Open Orders from both Manufacturers ("M-AD Open Order Comp A" and "M-BC Open Order Comp B") if Supplier wants to avoid skewed deliveries toward either of the Manufacturers to maintain customer relations with both Manufacturers.

First, S-AB Profitability is designed as neutral. As shown in Table 5, the four Components are designed so that the cycle time of Components A per unit ("S-AB Cycle Time CompA") is twice as long as that of Components B ("S-AB Cycle Time CompB"). It means that it would take the same length of time to produce each Sales Lot of any Component, and to gain the same amount of sales. The Game being played, S-AB Profitability would depend on Supplier AB's perception of his skills of assembling respective Components and further by price negotiation with Manufacturers. Likewise, S-AB Defect Risk, S-AB Production Change-Over and S-AB Timely Delivery Assurance depend on his perception per his skills and on judgment of his situations.

The CLS also confirms that there are no reinforcing loops but two balancing loops, named Comp A Delivery Loop and Comp B Delivery Loop, in Fig. 2. S-AB Component Priority has both positive and negative causal relations with the delivery rate of Component A ("S-AB Delivery Rate CompA") and that of Component B ("S-AB Delivery Rate CompB"), respectively. The number of Component A units received by Manufacturer AD ("M-AD Receipt Rate CompA"), which is equal to S-AB Delivery Rate CompA, decreases M-AD Open Order Comp A; i.e. S-AB Delivery Rate CompA has a negative causal relation with M-AD Open Order Comp A. M-AD Open Order Comp A then has a positive causal relation with S-AB Component Priority. So, the loop regarding order and delivery of Component A forms a balancing loop ("Comp A Delivery Loop"), and the same principle applies for Comp B Delivery Loop. 


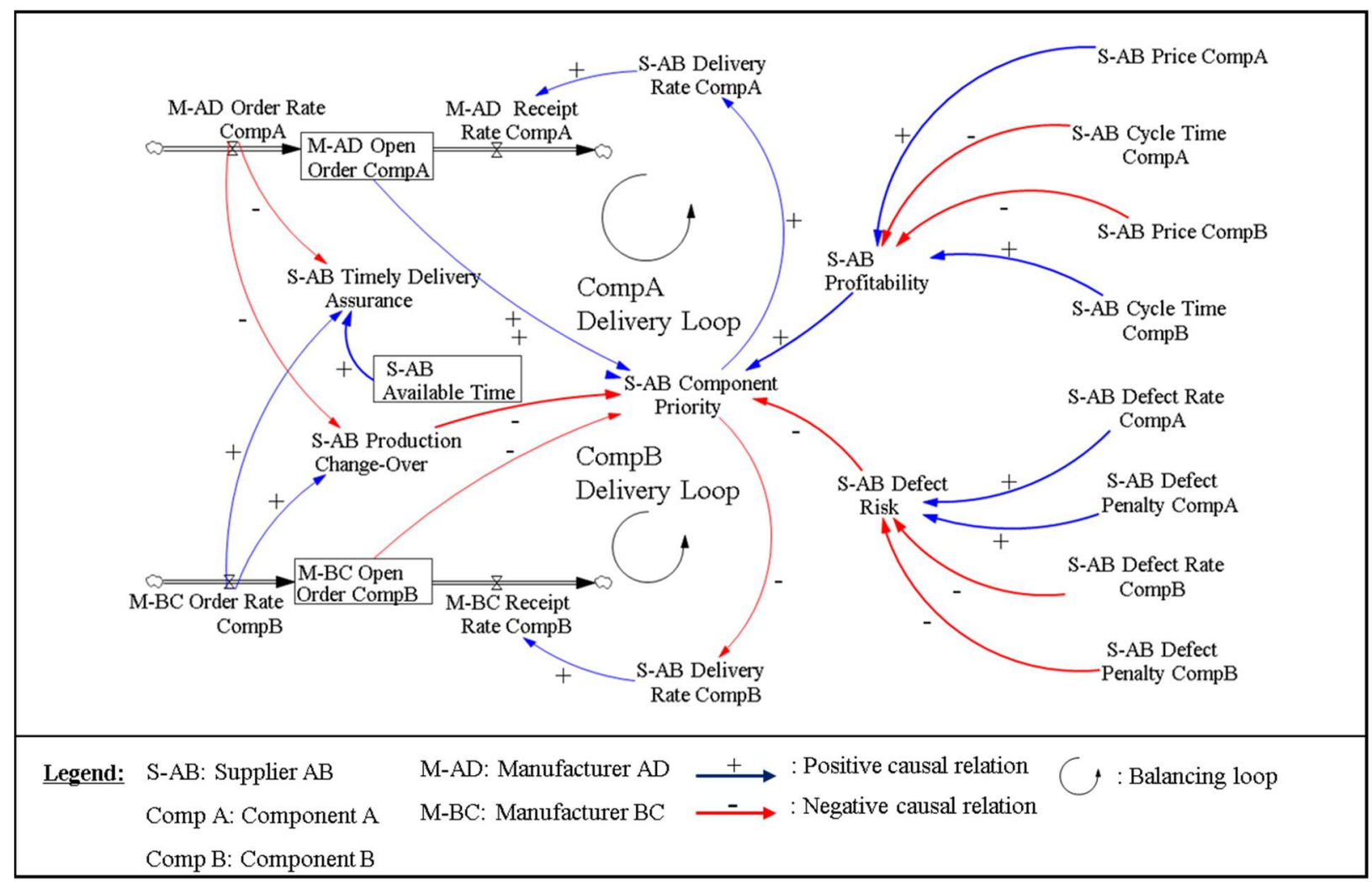

Fig. 2 Illustration of Supplier's Mental Model to Determine His Component Priority.

Note 1: The above illustrates that a pair (upper and lower side) of SFM's and four key variables form Component Priority A/B. The left-hand side of the illustration shows that Manufacturer's Order Rate affects Timely Delivery Assurance and Production Change-Over, while the right-hand side shows that Suppliers' skill-attributable variables, such as Cycle Time and Defect Rate, and trading terms variables, such as Price and Defect Penalty affect Profitability and Defect Risk.

Note 2: Two balancing loops show that the nature of this SC enables a balance of Delivery Rates of two components. At the same time, the above suggests options which Manufacturers and Suppliers can control to optimize their KPIs.

Further, unlike Beer Distribution Game, Suppliers' and Manufacturers' activities are visible to one another so that no material time delay is caused in response to behaviors taken by other participants in SC. So, there is only a small chance that this design of the Game would cause material oscillations of performance or trade-offs between short- and long-term effects in the gameplay. Hence, the CLD suggests a possibility that this Game design does not create a systemic tendency of SC, and that the Game meets Key Requirement A of Table 8.

\subsection{Design to Create Participants' Need to Understand Others' Mental Model}

Figure 2 indicates the possibility that Suppliers' Component Priority is subject to their decision over the trade-off between the Defect Risk and Profitability. At the same time, Fig. 2 shows that Manufacturer's Order Rate affects Production Change-Over and Timely Delivery Assurance. A Supplier may feel more comfortable with repeating the same operations; i.e. a larger Order Rate for Component A negatively affects Production Change-Over. Another Supplier may seek Timely Delivery Assurance by a smaller Order Rate; i.e. a larger Order Rate negatively affects Timely Delivery Assurance, while Timely Delivery Assurance is also subject to available time to produce in each round (“Available Time").

Hence, the CLD shows that the Order Rate is the variable available for Manufacturers to influence a Supplier in the gameplay. If Manufacturers are rational, they need to determine an Order Rate in line with their assumptions regarding which factor - Production Change-Over or Timely Delivery Assurance - better affects Suppliers' determination of Component Priority. Therefore, Manufacturers need to continuously observe Suppliers' behaviors to 
verify their assumptions and to timely adjust their Order Rate within each round. This context the Game creates is expected to satisfy Key Requirement B of Table 8, providing a learning opportunity about the importance of understanding stakeholders' interest and of managing a control variable, i.e. adjusting their decisions and/or behaviors with a purpose.

\subsection{Change of Rules and KPI over Rounds}

Finding of a limited number of control variables available in the Game in Section 3.2 also suggests that learning opportunities of the Game can be enriched by making more variables controllable for participants. If Supplier and Manufacturer can negotiate on trading terms and other operational considerations, it will allow them to control the following additional variables to affect Component Priority and to optimize their KPI as follows:

a Prices and Defect Penalty: considering Manufacturer's goal to improve his Income, Supplier can bargain on these,

b Order Rate: Supplier can share their preferences, considering Timely Delivery Assurance and Production Change-Over, and

c Cycle Time and Defect Risk; Supplier and Manufacturer can discuss how to improve Supplier's skills as well as how to fix defects.

Hence, as summarized in Table 3, Round 1 is designed in accordance with the original game concept. In Round 2, individual Income continues to be the KPI for each role. Changes in the Game's rules are designed by allowing each Manufacturer and each Supplier to negotiate to seek optimization of their individual Income. The changes make the participants build their own negotiation strategy to maximize their income; i.e. it enables Manufacturer and Supplier to verbally influence each other, attempting to manage available control variables. If they misunderstand the nature of their counterparts' interests, heuristics, and position against the others, they are likely to fail in negotiation for improving their KPI.

Round 3 is also added to further allow the roles in SC to design SC's structure and processes through collaboration, to maximize SC's total income, while the interactions of SC with Customer do not change. SC's total income is computed only by means of the interactions with the Customer as follows:

Total Finished Goods Revenue - Total Penalty for backorder and for defect - Total inventory cost.

This change of KPIs is designed to create motivation for collectively manage Conflict of KPIs. To enhance learning about collaboration through experiencing changes in each participant's thoughts and behaviors, no discussion or negotiation is required on how to allocate SC's total income. Therefore, these three rounds of different rules are expected to meet Key Requirement $\mathrm{C}$ of Table 8, creating different contexts to drive each participant's change of behaviors.

In summary, the system dynamics is used to design interactions among the participants in the business game to enrich participants' learning experience. Figure 2 diagrams Supplier's mental model and confirms the possibility that the design of the Game minimizes systemic tendency of SC's' behaviors, but provide insights for importance of understanding stakeholders' mental model to optimize their performance. It further eye-opens an opportunity to enrich learning experience by changing the Game's rule over rounds to offer an increased number of control variables to influence.

\section{Experimental Results}

\subsection{Experimental Method}

To evaluate the effectiveness of the Game against the Key Requirements discussed above, three business game sessions were held. A total of seventeen students and professionals ("samples") participated, with one sample in each session taking the Customer role. The first two sessions invited 4 samples to play two Suppliers and two Manufacturers roles, while the last session had six samples, including two pairs of them playing Suppliers roles and the remaining two playing Manufacturers roles. Three samples, one in each session, played the Customer role. Their responses are included in overall evaluation in Table 9. 
Both quantitative and qualitative methods were used to evaluate the Game, including:

- $\quad$ Feedback to a written questionnaire after the game ("Feedback"),

- Notes of strategy and its reflection for each round ("Strategy Note"),

- Follow-up interviews with selected participants, and

- Participatory observation during the game, including those of the participants' discussion in the debriefing and oral feedback gained immediately after the game.

Two samples responded twice because they participated in both Sessions $1 \& 3$, playing different roles.

\subsection{Experimental Results}

The above experiment resulted in an indication that the Game is effective in providing a learning opportunity to develop skills required to manage Conflict of KPIs for improving supply chain performance, and that the Game design meet all Key Requirements.

Overall evaluation obtained from the written questionnaire suggests the possibility that the Game effectively provides a learning opportunity for participants to develop skills to manage Conflict of KPIs. Table 9 shows that the samples generally affirmed the value of this Game against the time spent; $92.3 \%$ rated their experience 5 or higher with a mean value of 5.54. The highest level of agreement was given to their willingness to recommend this Game to others; $100 \%$ of the samples rated 5 (somewhat agree) to 7 (fully agree) with a mean value of 6.35 .

In the Feedback, the sample who had played supply-chain-related business games before this Game stated, "it is the nature of business games to over-simplify the real business environment," but said, "I could find aspects like real situations to improve on each round" in this Game.

Figure 3 shows changes of individual Incomes of the four roles over the first two rounds. This result indicates a possibility that a change of available control variables affects the samples' behaviors and their interactions, resulting in different paths of their performance trend. Despite of Supplier's strong position against Manufacturers by nature of Round 2 rules design, Fig. 3 and Fig. 4 show that in Round 2, Supplier worsened his performance, or a Manufacturer improved his by negotiation. It suggests that there be no systemic tendency of each role's behavior in the first two rounds, but the result depends on what kind of a conflict they may encounter and on how to manage such a conflict (Refer to Key Requirement A of Table 8).

In Session 2, not only Supplier CD but the total SC decreased their Income in Round 2, as the numbers of defects and backorders increased except Supplier AB as shown in Fig. 4. The sample of Supplier CD said in his Feedback, "I did not properly understand pricing, my position (power relationship) and the structure of profit." However, Manufacturers could not take it as their advantage, but generated loss together with Supplier CD. Sourcing of Components became a bottleneck of Manufacturers, affecting net delivery. In addition to the quality issue of Components from Supplier CD, Manufacturers suffered from waiting for receiving either or both of Components and from consequent Backorder Penalty. Figure 4 tells how important it is to mitigate Manufacturers' bottleneck, i.e. to control backorders, for better performance in this Game. There was an observatory indication in Round 1 that Supplier CD's productivity could be a bottleneck for improving SC's performance. However, Manufacturers did not successfully provide support for Supplier CD's productivity to improve their own Income, but focused on negotiation of the trading terms. In the debriefing after this Session, the samples realized that Manufacturers had needed to consider how to mitigate their bottleneck in sourcing by understanding Suppliers' interests for their own.

In contrast, in Session 3 not only Suppliers but Manufacturer BC improved his Income in Round 2, as the numbers of defects and backorders decreased as shown in Fig. 4. Per his Strategy Note for Round 1, he chose to place a larger order than he received from the Customer in Round 1. He aimed to get full of Suppliers' resources to be deployed for

Table 9 Overall Evaluation ${ }^{(1)}$.

\begin{tabular}{lrrr}
\hline \multicolumn{1}{c}{ Statement } & $\begin{array}{c}\text { Positive } \\
\text { Response } \% \\
(\geq 5)\end{array}$ & Mean & SD \\
\hline I think 3.5 hours is worth spending to learn what I have gained. $(\mathrm{n}=13)$ & $92.3 \%$ & 5.54 & 1.05 \\
I recommend this business game to other people. (n=17) & $100.0 \%$ & 6.35 & 0.61 \\
$\begin{array}{l}\text { I can leverage the experiences or insights ... in my business or in } \\
\quad \text { whatever project I am/will be engaged. (n=16) }\end{array}$ & $93.8 \%$ & 5.75 & 0.77 \\
\hline
\end{tabular}

-Note 1: Overall evaluation is based on answers to the above statements by Likert scale ranging from "Fully disagree" (1) through "Neutral" (4), "Somewhat agree (5) and "Agree" (6) to "Fully Agree (7). 
himself to disrupt Manufacturer AD's activity. In his Feedback, he stated, "even if I tried to assume how other players would rationally think to maximize their profit and act in the negotiation, they took different approaches." However, he improved his Income in Round 2 by offering opportunities to improve Suppliers' productivity by introducing one-piece-flow operations and by fostering mutual communication. Such negotiation styles not only improved his Income in Round 2 but also contributed to increase SC's Total Income as shown in Fig. 5. Sharing their mind model in the debriefing, the samples learned what had gone well and what had not for their own performance and SC's, and their reasons associated with interactions with other roles. Hence, both samples' experiences above suggest a possibility that it is fundamental for high performance in the Game to understand other roles' and whole SC's needs through interactions with others (Refer to Key Requirement B of Table 8).

Figure 5 shows the progress of SC's total income over the three rounds. SC of Session 1 and Session 2 experienced negative total income in Round 2, where Conflict of KPIs transformed by the samples' negotiations appears to result in damaging SC's performance (Refer to Key Requirement C of Table 8). One sample in Session 2 reflected his experience and stated

"As a result of negotiation, SC's whole income was negative. Each player was pursuing an individual optimum, and the uncertainty of human behavior added to it, I was surprised at how much performance worsens."

Individual Income $(\$ 1,000)$

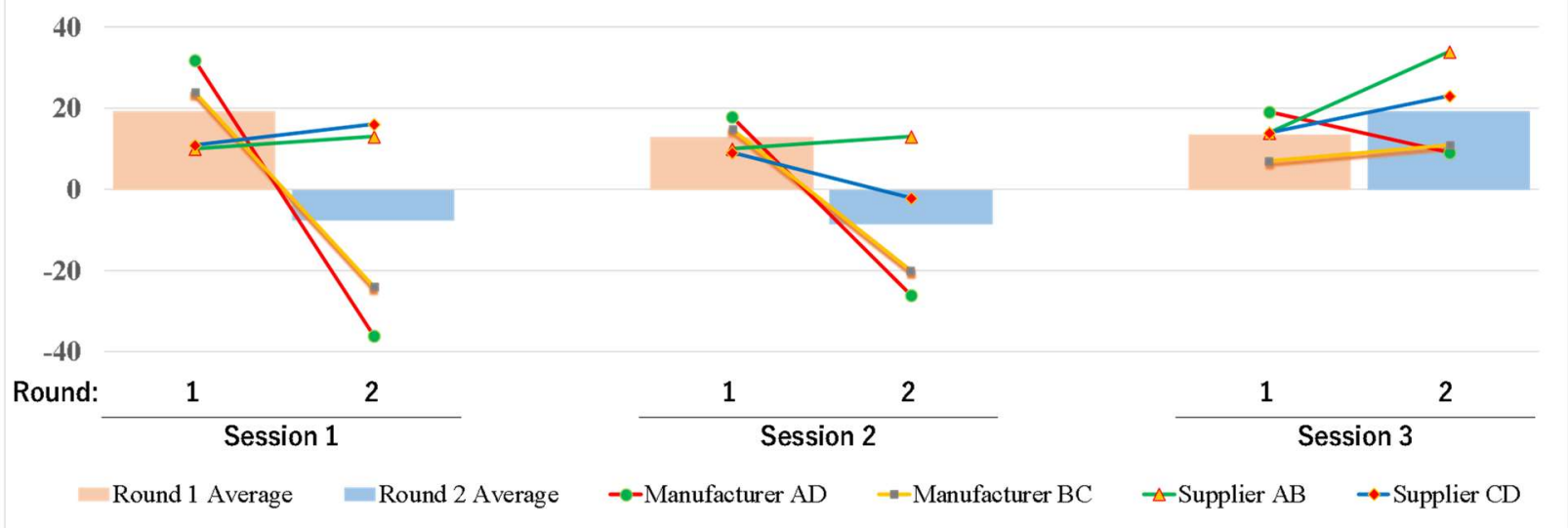

Fig. 3 Average and Individual Incomes over the First Two Rounds ${ }^{(1)}$.

Note 1: There is no data for Round 3, as no individual income is measured per KPI for Round 3 (See Table 3).

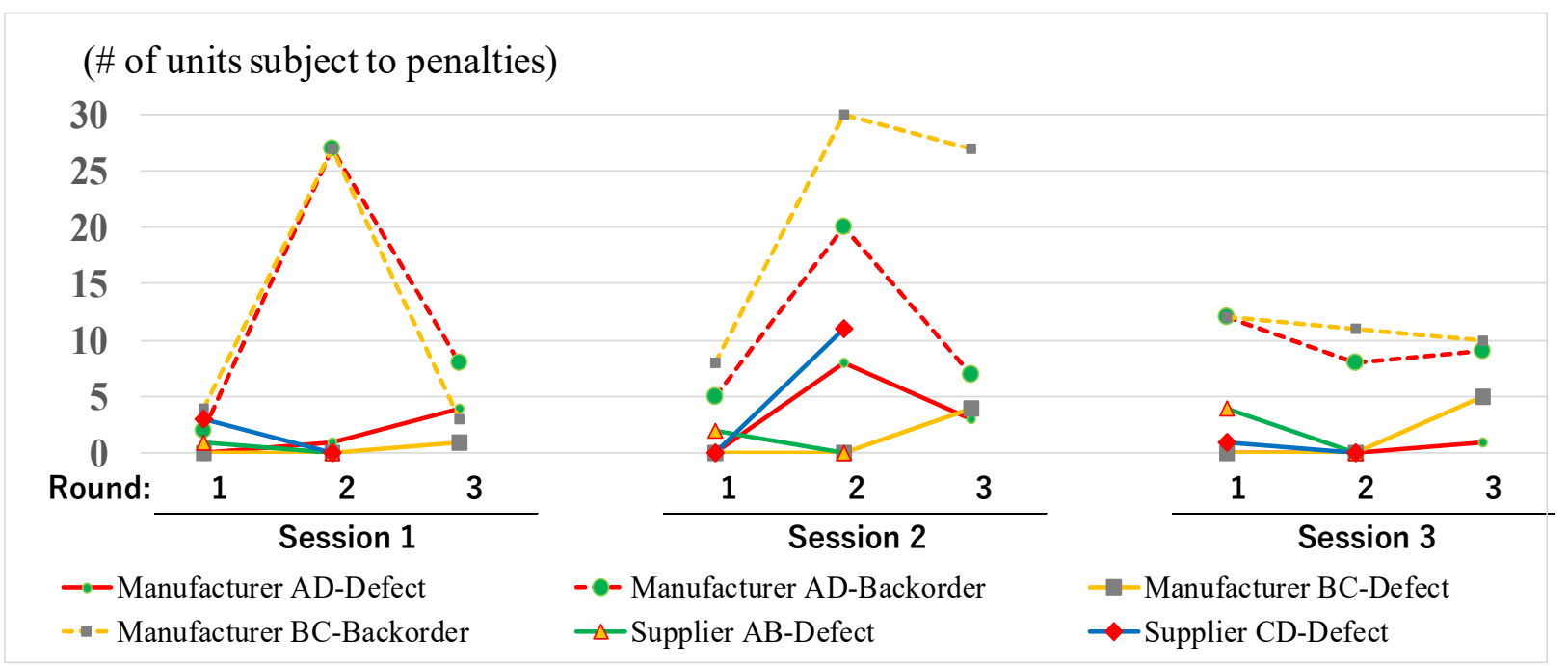

Fig. 4 Number of Units subject to Penalties over the Three Rounds ${ }^{(1)}$.

Note 1: Only Manufacturers are subject to Backorder Penalty (See Table 5 and Table 6). No data of Suppliers are measured in Round 3. 
Even worse, Session 2 resulted in reduction of SC Income from Round 1 to Round 3. The afore-mentioned sample of Supplier CD in Session 2 also commented on how SC worked in Round 3, describing "I feel we did not discuss the review of tasks and flows well. We did not have enough time to talk. After all we were divided into two groups, each of them finished products, and we were not released from the composition of 'competition'. It cannot not be said that we shared our wisdom about what we could have changed by leveraging cooperation."

There was the following reflection from another sample of the same session, "I thought that the result was so bad proving that lack of cooperation messes up supply chain systems" and "As it happened also in this game session, human communication is probably the most important aspect of business." This indicates their experiential insights into what would affect quality of collaboration as acquired through different contexts to drive different participants' behaviors (Refer to Key Requirement C of Table 8).

On the other hand, Fig. 5 shows that SC improved their total performance in Session 3, by negotiation, and furthered by collaboration. There seems to be two sources of the sampling bias that influenced on the stable improvement. First, three samples of Session 3 have experienced Session 1 or the final prototype of the Game prior to the experiment ("Repeaters"). Instead, it may indicate that the successful growth of SC's Income in Session 3 is attributable to their effective learning from their previous session to manage Conflict of KPIs. Second, a supply chain training professional from one of the top global enterprises in beverage industry joined Session 3 as Supplier AB and seemed to demonstrate his agility in this context and affect the whole SC.

However, more importantly, the supply chain training professional fed back his learning experience, saying, "I was impressed by experiencing that sharing a common KPI affects the change in [the samples'] mindset and consequential communication and behavior, which results in a drastic improvement." In addition, the above three Repeaters all agreed to "recommend others to participate in the Game more than once," and supported re-playability of the Game.

In summary, the above experimental results suggest the possibility that the Game provides participants with experiential learning about interpersonal skills at managing Conflict of KPIs, and the Game meet all Key Requirements specified in Table 8.

\section{(\# of Units, \$1,000)}

150

100
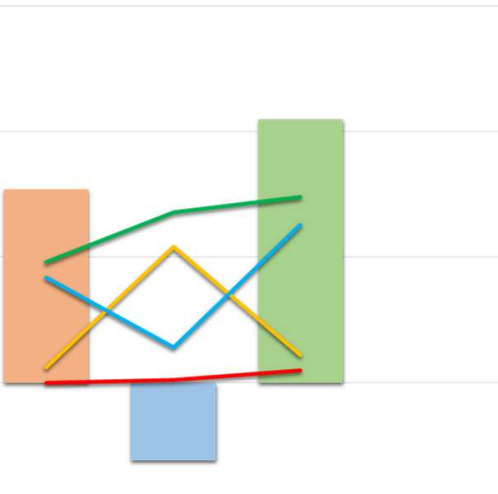

$-50$

Round 1 Round 2 Round 3 Session 1
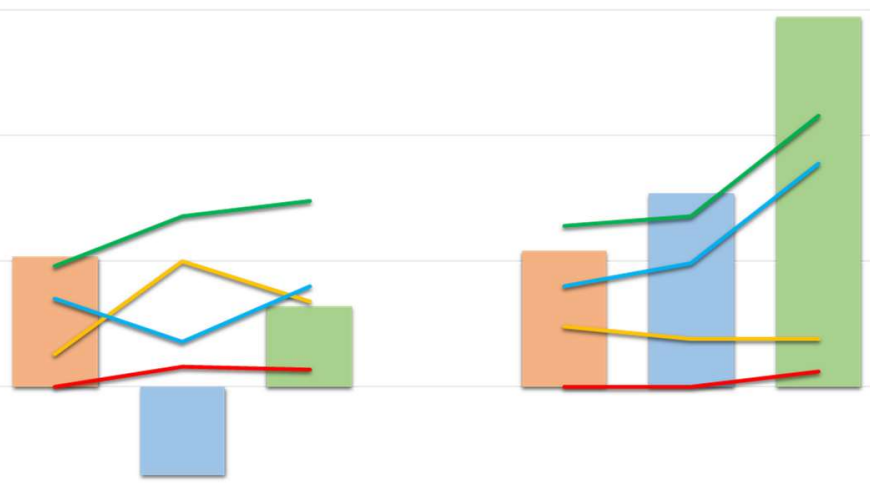

$\begin{array}{lccc}\square \text { Round } 1 \mathrm{SC} \text { Income } & \text { Round } 2 \mathrm{SC} \text { Income } & \\ \text {-Customer Orders } & \text {-Defect } & \text { Round 3 SC Income } & \\ & \text {-Backorder } & \text {-Net Delivery }\end{array}$

Fig. 5 SC Total Income over the Three Rounds ${ }^{(1),(2) .}$

Note 1: Absolute values of SC's total income do not represent learning effectiveness for each sample or for a group of each session but depend more on samples' skills of assembling parts into components and components into finished goods as well as portfolio of samples in each session.

Note 2: Due to a difference of sample size of Session 3 from the first two sessions, its total income is not comparable to other sessions'. However, the trend, increase and/or decrease, of SC's total income reflects results from interactions among the samples that alter over three rounds. 


\section{Discussion}

The changes of the rules over rounds, as discussed in Section 4, suggests that the Game provides learning about how changes of constraints or available control variables affect individuals' behaviors, and about the importance of removing constraints and finding space to collaborate with other stakeholders to improve organizational performance. While the mental model of each Supplier and Manufacturer, aiming at local optimization in the first two rounds, has been analyzed, that in Round 3 has yet to be analyzed. The mental model of participants aiming at global optimization appears to post an opportunity for research to identify any elements to enhance collaboration in Conflict of KPIs.

In addition, there is a possibility of the Game's applicability for educating on how to improve program management's performance, since the Game creates a context where time allocation of Suppliers is a source of conflict. In the context of program management, where process owners need to concurrently deploy their resources to multiple projects and encounter their resource constraints. Project managers then need to get alignment with the process owners' resource allocation. The program manager of such organization needs to figure out how to optimize the overall program performance by managing conflict between the projects. It means that process owners' roles sit well as Suppliers, and project management roles do as Manufacturers in this Game. Accordingly, the Game has a possibility to serve for project and program management to develop their talents. At the same time, the heuristics of participants in the Game can also be discussed from the perspectives of project and program management.

\section{Conclusion}

In this research, system dynamics is applied to develop a game to foster skills required to manage Conflict of KPIs for improving supply chain performance. Concept design started with a structure of a two-tier supply chain, where two manufacturers source their components from a pair of suppliers. In contrast to the Beer Distribution Game, the CANDY OG Game design attempts to minimize a systemic tendency of each role's behaviors, but to maximize the influence of interactions among the participants under Conflict of KPIs on their performance. A causal loop diagram suggests the possibility that each role's behaviors and performance are not subject to any systemic effect of the game design, but largely depend on participants' interaction. The use of system dynamics in the design of this Game further provides insight for enriching learning experience by changing rules over three rounds. Thus, it offers to participants an increased number of control variables as rounds of the Game progress.

The experimental results also appear to confirm that system dynamics provides insightful analyses into the effect of changes in available control variables on creating a contrast of samples' behaviors. Thus, there is an indication by the experiments that system dynamics is an effective design tool of a business game that provides a learning about managing Conflict of KPIs by enriching interpersonal experiences in a simulated context.

Limitations of this research include the small number of samples for evaluating this Game, especially from a population of supply chain professionals; and the lack of evaluation by different facilitators. Given these limitations, however, the experimental results indicate the possibility that the Game is designed as an effective learning method to satisfy the key learning objectives specified in Table 1. Hence, application of system dynamics appears valid in developing business games to provide interpersonal skills development by focusing on participants' mental model.

\section{References}

Asgari, N., Nikbakhsh, E., Hill, A. and Farahani, R. Z., Supply chain management 1982-2015: A review, IMA Journal of Management Mathematics, Vol.27, No.3 (2016), pp.353-379.

Cai, J., Liu, X., Xiao, Z. and Liu, J., Improving supply chain performance management: A systematic approach to analyzing iterative KPI accomplishment, Decision Support Systems, Vol.46, No.2 (2009), pp.512-521.

Christopher, M., Logistics and Supply Chain Management; Strategies for reducing cost and improving service (1998), pp.18-19, Financial Times Management Pitman Publishing.

Crookall, D., Serious games, debriefing, and simulation/gaming as a discipline, Simulation \& Gaming, Vol.41, No.6 (2011), pp.898-920.

Ding, H., Guo, B. and Liu, Z., Information sharing and profit allotment based on supply chain cooperation, International Journal of Production Economics, Vol.133, No.1 (2011), pp.70-79. 
Domínguez, A., Saenz-de-Navarrete, J., De-Marcos, L., Fernández-Sanz, L., Pagés, C. and Martínez-Herráiz, J., Gamifying learning experiences: Practical implications and outcomes, Computers \& Education, Vol.63 (2013), pp.380-392.

Hassini, E., Supply chain optimization: Current practices and overview of emerging research opportunities, INFOR, Vol.46, No.2 (2008), pp.93-96.

Kaminsky, P. and Simchi-Levi, D, A new computerized beer game: A tool for teaching the value of integrated supply chain management, Supply Chain and Technology Management, Vol.1 (1998), pp.216-225.

Kleijnen, J. P. C. and Smits, M. T., Performance metrics in supply chain management, Journal of the Operational Research Society, Vol.54, No.5 (2003), pp.507-514.

Kriz, W. C., Creating effective learning environments and learning organizations through gaming simulation design, Simulation \& Gaming, Vo.34, No.4 (2003), pp.495-511.

Locke, E.A. and Latham, G. P., New directions in goal-setting theory, Current Directions in Psychological Science, Vol.15, No.5 (2006), pp.265-268.

Panahifar, F., Heavey, C., Byrne, P. J. and Fazlollahtabar, H., A framework for Collaborative Planning, Forecasting and Replenishment (CPFR): State of the art, Journal of Enterprise Information Vol.28, No.6 (2015), pp.838-871.

Parung, J. and Bititci, U. S., A Metric for Collaborative Networks, Business Process Management Journal, Vol. 14, No5 (2008), pp.654-674.

Raybourn, E. M., Applying simulation experience design methods to creating serious game-based adaptive training systems, Interacting with Computers, Vol.19, No.2 (2007), pp.206-214.

Skjoett - Larsen, T., Thernøe, C. and Andresen, C., Supply chain collaboration, International Journal of Physical Distribution \& Logistics Management, Vol. 33, No.6 (2003), pp.531-549.

Sterman, J. D., Business Dynamics - System Thinking and Modeling for a Complex World (2000), p.vii, Shelstad.

Sterman, J. D., Modeling managerial behavior: Misperceptions of feedback in a dynamic decision making, Management Science, Vol.35, No.3 (1989), pp.321-339.

Supply Chain Operations, Supply Chain Operations Reference (SCOR ®) Model (2010), pp.5-6

Winn, B. M., The design, play, and experience framework, Handbook of Research on Effective Electronic Gaming in Education (2009), pp.1010-1024, IGI Global. 